\title{
OPTIMIZATION OF IN-SITU TRANSESTERIFICATION PROCESS OF BIODIESEL FROM NYAMPLUNG (Calophyllum inophyllum L.) SEED USING MICROWAVE
}

\author{
L. Qadariyah", S.N. Syahir, A. Fyadlon, D.S. Bhuana and M. Mahfud* \\ Department of Chemical Engineering, Faculty of Industrial Technology, Institut Teknologi \\ Sepuluh Nopember, 60111, Indonesia \\ *E-mail: lailatul_2008@yahoo.com; mahfud@chem-eng.its.ac.id
}

\begin{abstract}
The purpose of this study was to optimize the in-situ transesterification process of biodiesel from nyamplung (Calophyllum inophyllum L.) seed using the microwave. In this study, three independent variables (microwave power, $\mathrm{KOH}$ concentration and in-situ transesterification time) were explored. The optimum in-situ transesterification conditions obtained by Box-Behnken Design (BBD) were as follows: microwave power 502.124 $\mathrm{W}, \mathrm{KOH}$ concentration $0.499241 \%$ and in-situ transesterification time $19.0717 \mathrm{~min}$. Under these optimized conditions, the yield of biodiesel reached $60.5887 \%$. The predicted values indicated that the model equation for optimization of the in-situ transesterification process of biodiesel from nyamplung (Calophyllum inophyllum L.) seed by response surface method was matched reasonably well in accordance with the actual observed values. It can be seen from the suitability of the model equation for predicting the central point response value that was tested under the central point conditions.
\end{abstract}

Keywords: biodiesel; Box-Behnken design; Calophyllum inophyllum L.; in-situ transesterification; microwave.

(C) RASĀYAN. All rights reserved

\section{INTRODUCTION}

Fuel is one of the energy sources that have an important role in human life. The increasing depletion of fossil energy and the increasing demand for fuel resulted in rising world oil prices. In addition, because of the nature of fossil fuels that are not renewable, it must be found a new oil source so there is no fuel scarcity. To avoid the occurrence of the energy crisis, then one thing that can be done is to make fuel savings. In addition to making savings, one of the efforts to overcome the energy crisis is the replacement of fossil fuels with renewable alternative fuels.

Biodiesel is an alternative fuel produced from renewable biological resources such as vegetable oils or animal fats ${ }^{1}$. Biodiesel is produced from the transesterification process of triglycerides by methanol or ethanol reactants and acid or base catalysts. Biodiesel from vegetable oil, in general, has characteristics approaching fuel derived from petroleum. In addition, biodiesel from vegetable oils is renewable so that its availability is more secure and its production can be further improved. Therefore need to be developed an alternative fuel that is biodiesel made from vegetable oil, one of them is derived from nyamplung (Calophyllum inophyllum L.) seed.

In general, the process of making biodiesel through the stages of oil extraction, purification of oil and stages of esterification-transesterification from oil to biodiesel. The long stages that must be passed lead to low efficiency and high energy consumption, which resulted in the cost of producing biodiesel. Therefore, it is necessary to develop a process of making biodiesel that more effective, efficient and energy saving and can produce high-quality biodiesel through in-situ transesterification process. The in situ transesterification process is a simpler step in producing biodiesel by eliminating the extraction and purification processes so that it can lower production costs ${ }^{2}$. In-situ transesterification is the process of oil extraction and the transesterification reaction that is carried out simultaneously. In addition to more efficient, this process will also shorten the time because the process of conversion of raw materials into biodiesel is done simultaneously with oil extraction process.

Rasayan J. Chem., 10(3), 952-958(2017)

http://dx.doi.org/10.7324/RJC.2017.1031803 
Therefore, in this research will be studied biodiesel production process from nyamplung (Calophyllum inophyllum L.) seed through in-situ transesterification process using the microwave.

Response surface methodology (RSM) is an alternate strategy involving statistical approach compared to one variable at a time, which could reflect the effect of interaction between different factors ${ }^{3}$. RSM using Box-Behnken designs have treatment combinations that are at the midpoints of the edges of the experimental space and require at least three continuous factors. Box-Behnken design is a type of response surface design that does not contain an embedded factorial or fractional factorial design. The main advantages of RSM are the reduced numbers of experimental trials which need to evaluate multiple parameters and their interactions and it is useful for developing, improving, and optimizing the process ${ }^{4}$. In recent years, RSM has been widely used in analyzing various biological processes, designing the experiment, building models, evaluating the effects of several factors, and searching for optimum conditions to acquire desirable responses and reducing the number of experiments ${ }^{5,6,7,8}$. Since many operating factors were involved in the in-situ transesterification process of biodiesel from nyamplung (Calophyllum inophyllum L.) seed using the microwave, RSM was used as an appropriate approach to analyze the in-situ transesterification process.

\section{Raw Material}

\section{EXPERIMENTAL}

The main raw material used in this study is nyamplung (Calophyllum inophyllum L.) seed. All other chemicals and solvents used were of analytical grade.

\section{In-Situ Transesterification Process of Biodiesel from Nyamplung (Calophyllum inophyllum L.) Seed using Microwave}

A domestic microwave oven (EMM2308X, Electrolux, $23 \mathrm{~L}, 800 \mathrm{~W} ; 2.45 \mathrm{GHz}$ ) was modified for in-situ transesterification process of biodiesel. The dimensions of the PTFE-coated cavity of microwave oven were $48.5 \mathrm{~cm}$ x $37.0 \mathrm{~cm}$ x $29.25 \mathrm{~cm}$. Various $\mathrm{KOH}$ concentration $(0.10,0.20,0.30,0.40$ and $0.50 \mathrm{~g} / \mathrm{mL})$ were placed in a $1 \mathrm{~L}$ flask containing methanol and nyamplung (Calophyllum inophyllum L.) seed (100 g). The flask was setup within microwave oven cavity and a reflux condenser was used in order to prevent loss of solvent due to vaporization thus maintaining the solvent volume in the reaction mixture throughout the experiments (Fig.-1). The microwave oven was operated at 300, 450 and $600 \mathrm{~W}$ power level for a period of 10,20 and $30 \mathrm{~min}$.

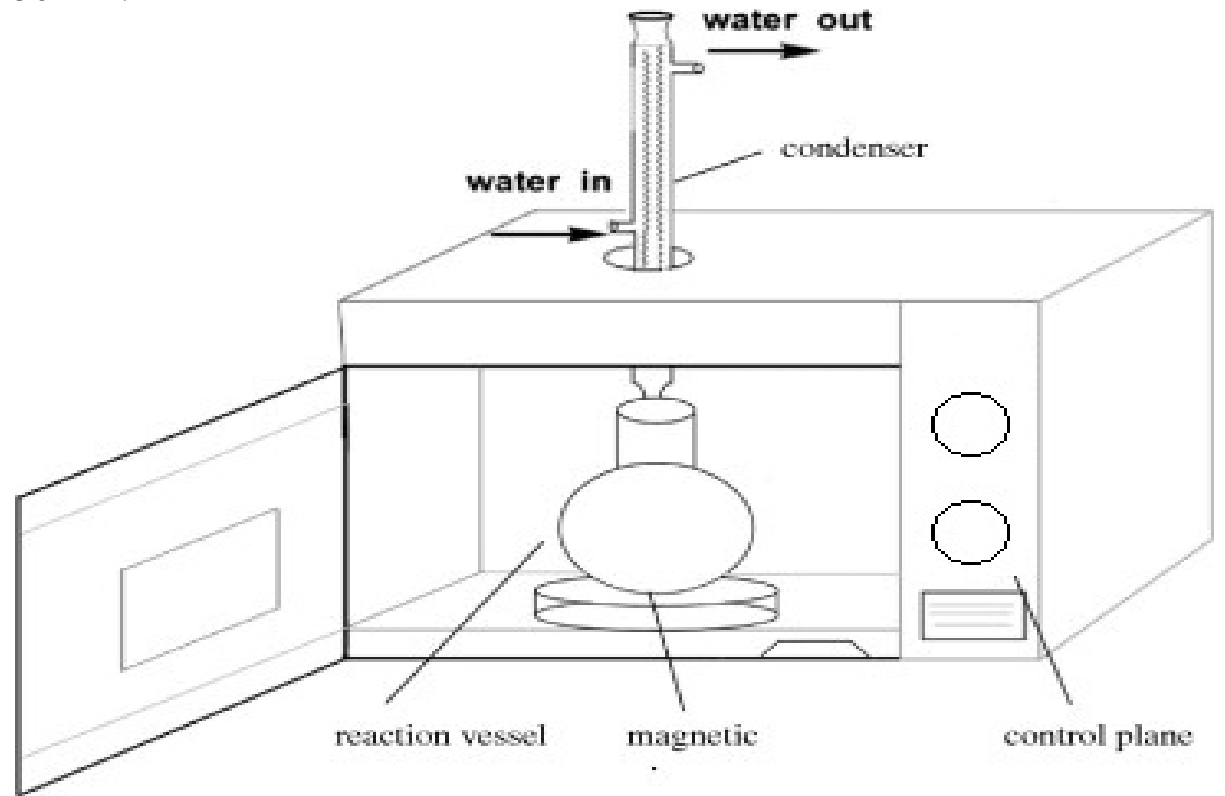

Fig.-1: Schematic representation of in-situ transesterification process of biodiesel from nyamplung (Calophyllum inophyllum L.) seed using the microwave 
As the reaction was stopped, the product was kept in separating funnel over night for separating biodiesel and glycerol. After separating the lower glycerol layer from the upper layer of biodiesel, the upper layer was collected for further purification. The biodiesel was first washed with glacial acetic acid mixed in hot water and then washed only with plain hot water for two times. The biodiesel yield was calculated relative to the initial amount of nyamplung (Calophyllum inophyllum L.) seed oil by weight and the biodiesel purity was determined according to the viscosity.

\section{Response Surface Method to Optimize the In-Situ Transesterification Process of Biodiesel}

A $2^{3}$ Box-Behnken Design (BBD) was employed resulting in a total of 17 experiments to optimize the selected three factors which had great influence on the experiment, including microwave power, $\mathrm{KOH}$ concentration and in-situ transesterification time, and on A, B and C said. In this research, A, B and C were used as independent variables while the yield of biodiesel as the response value (Y) to conduct the test. Design-Expert version 9.0.4.1 (State-Ease Inc., Minneapolis, MN, USA) was adopted to do a regression analysis of experimental data. Each independent variable of the low, medium and high level of the experiment was coded as $-1,0$ and 1 . The property of polynomial fitting model equation was expressed by the coefficient of determination. And its significance of statistical was verified by $\mathrm{F}$ value. The optimal conditions of in-situ transesterification and a maximum yield of biodiesel from nyamplung (Calophyllum inophyllum L.) seed using microwave were typically analyzed and predicted by Design-Expert version 9.0.4.1 (State-Ease Inc., Minneapolis, MN, USA).

\section{Effect of microwave power on the yield of biodiesel}

\section{RESULTS AND DISCUSSION}

The yield of biodiesel increased with the increasing microwave power. From Fig.-2, the yield of biodiesel increased the range of microwave power from $300 \mathrm{~W}$ to $600 \mathrm{~W}$. Accordingly, three microwave power levels including 300, 450 and $600 \mathrm{~W}$ were adopted to carry out the next experiment.

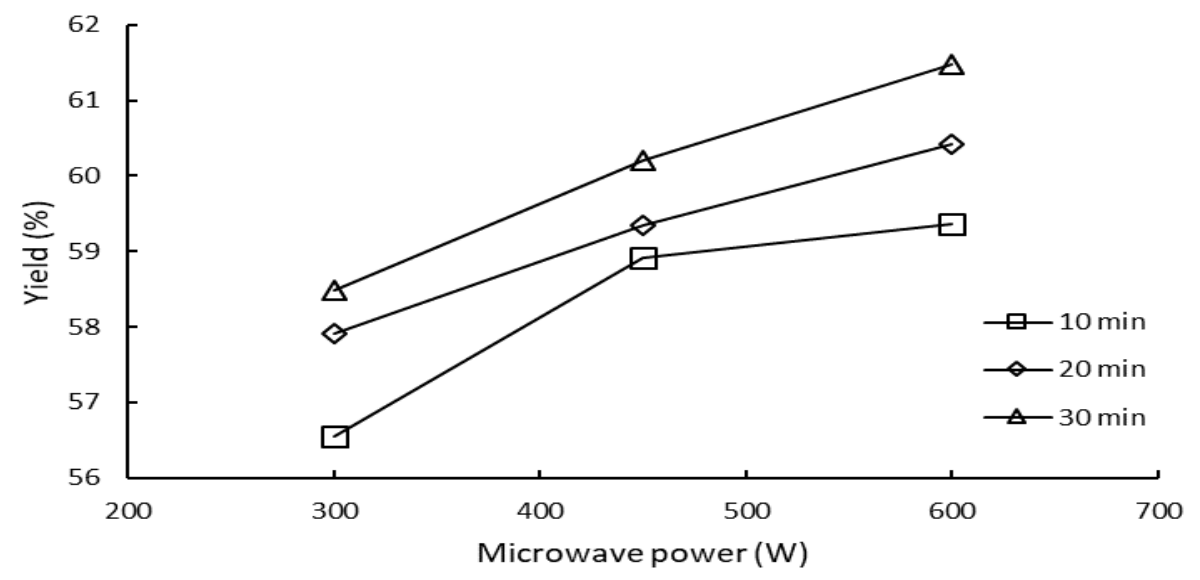

Fig.-2: The effect of microwave power on the yield of biodiesel $(\mathrm{KOH}$ concentration $=0.50 \%)$

\section{Effect of $\mathrm{KOH}$ concentration on the yield of biodiesel}

As seen from Fig.-3, the yield of biodiesel increased as $\mathrm{KOH}$ concentration increasing from the range of 0.10 to $0.50 \%$. As a result, three $\mathrm{KOH}$ concentration levels including $0.30,0.40$ and $0.50 \%$ were used to carry out the next experiment.

\section{Effect of in-situ transesterification time on the yield of biodiesel}

The effect of in-situ transesterification time on the yield of biodiesel is shown in Fig.-4, which indicates that the yield increased with the increasing in-situ transesterification time. The yield of biodiesel increased sharply after in-situ transesterification time reached $10 \mathrm{~min}$. Therefore, 10, 20 and $30 \mathrm{~min}$ were considered to carry out the next experiment. 
RASĀYAN J. Chem.

Vol. 10 | No. 3 |952 - 958 | July - September | 2017

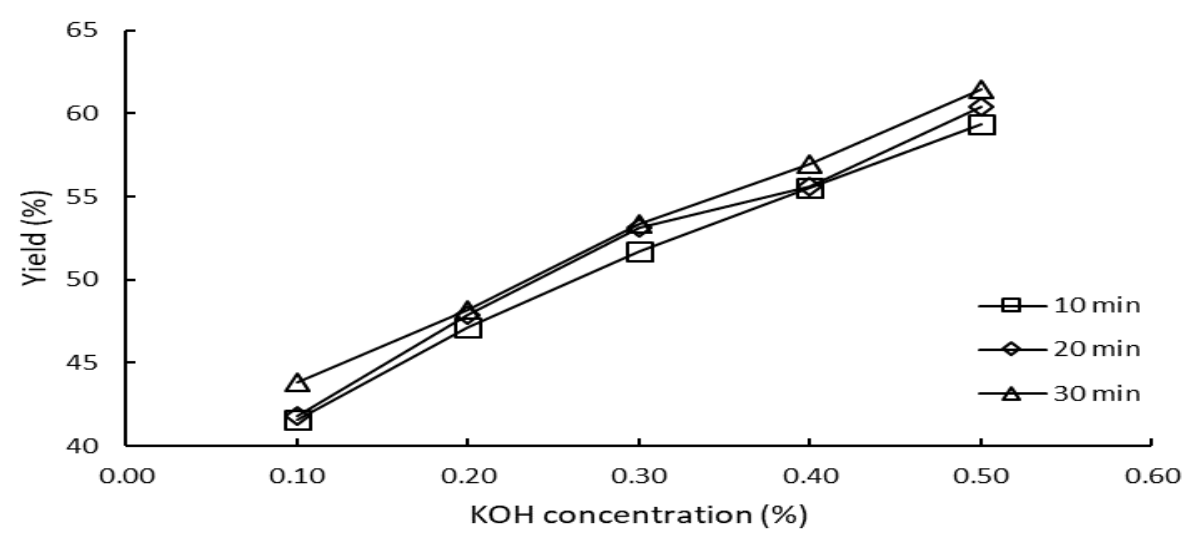

Fig.-3: The effect of $\mathrm{KOH}$ concentration $(\%)$ on the yield of biodiesel (microwave power $=600 \mathrm{~W}$ )

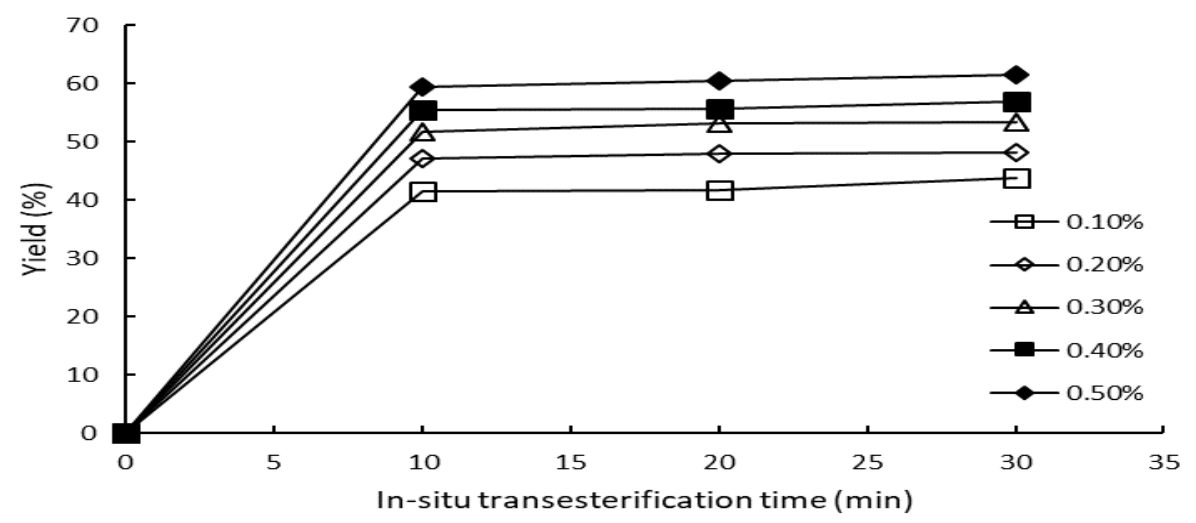

Fig.-4: The effect of in-situ transesterification time on the yield of biodiesel (microwave power $=600 \mathrm{~W}$ )

\section{Levels of independent variables for the Box-Behnken experimental design}

According to the theory of Box-Behnken experimental design, this research selected three factors that had great influence on the experiment, including microwave power, $\mathrm{KOH}$ concentration and in-situ transesterification time, and on $A, B$ and $C$ said. The three factors were coded at 3 levels, $-1,0$ and +1 (Table-1) which resulted in an experimental design of 17 experimental points, including 5 central points (Table-2). The other factorial experiment point was the summit where independent variables were the value at $A, B, C$. The null point was the central point of the area. And the zero test was repeated five times to calculate the test error.

\section{Analysis of variance and the regression equation}

The results of the second-order response surface model in the form of analysis of variance (ANOVA) were shown in Table-3. With analysis of variance (ANOVA), the second-order polynomial models were applied to calculate the predicted response as follows:

Yield $=-2.92130+0.048666 *$ Microwave power $+155.87538 * \mathrm{KOH}$ concentration $+0.52879 *$ In-situ transesterification time $-0.034028 *$ Microwave power* KOH concentration $+1.59567 \mathrm{E}-004 *$ Microwave power*In-situ transesterification time $-9.55000 \mathrm{E}-003 * \mathrm{KOH}$ concentration*In-situ transesterification time - 3.06717E-005*Microwave power $^{2}$ - $116.75625 * \mathrm{KOH}$ concentration $^{2}$ - $0.013482 *$ In-situ transesterification time ${ }^{2}$

The regression equation analysis and the significance test of the model were shown in Table-3. F-value and $\mathrm{p}$-value $(\mathrm{F}=67.56, \mathrm{p}<0.0001)$ of the model indicated that the regression model was very significant. These 
data suggest that the regression equation is fitted well in the fitting area and this model can be used to replacing the true experimental point to analyzing the experimental results.

Table-3 shows the main effect of microwave power (A); $\mathrm{KOH}$ concentration (B) and the in-situ transesterification time $(\mathrm{C})$ and the second-order effect of microwave power $\left(\mathrm{A}^{2}\right)$; $\mathrm{KOH}$ concentration $\left(\mathrm{B}^{2}\right)$ and the in-situ transesterification time $\left(\mathrm{C}^{2}\right)$ are the significant model terms. Other model terms are not significant (the two-level interactions of microwave power and $\mathrm{KOH}$ concentration $(\mathrm{AB})$; microwave power and the in-situ transesterification time (AC) and $\mathrm{KOH}$ concentration and the in-situ transesterification time (BC)). It implies that the relations between the model terms and factors are not only a linear correlation.

Table-1: Levels of independent variables used for optimization

\begin{tabular}{c|c|c|c}
\hline \multirow{2}{*}{ Factors } & \multicolumn{3}{|c}{ Levels } \\
\cline { 2 - 4 } & -1 & 0 & +1 \\
\hline A:Microwave power (W) & 300 & 450 & 600 \\
\hline B:KOH concentration (\%) & 0.30 & 0.40 & 0.50 \\
\hline C:In-situ transesterification time (min) & 10 & 20 & 30 \\
\hline
\end{tabular}

Table-2: The scheme and results of the Box-Behnken experimental design

\begin{tabular}{c|c|c|c|c}
\hline Run & $\begin{array}{c}\text { A:Microwave } \\
\text { power }(\mathrm{W})\end{array}$ & $\begin{array}{c}\text { B:KOH concentration } \\
(\%)\end{array}$ & $\begin{array}{c}\text { C:In-situ transesterification time } \\
(\mathrm{min})\end{array}$ & $\begin{array}{c}\text { Yield } \\
(\%)\end{array}$ \\
\hline 1 & 450 & 0.4 & 20 & 56.8541 \\
\hline 2 & 600 & 0.4 & 30 & 56.9773 \\
\hline 3 & 300 & 0.4 & 30 & 53.6566 \\
\hline 4 & 450 & 0.4 & 20 & 56.8541 \\
\hline 5 & 450 & 0.4 & 20 & 56.8541 \\
\hline 6 & 600 & 0.4 & 10 & 55.4962 \\
\hline 7 & 300 & 0.3 & 20 & 48.5444 \\
\hline 8 & 450 & 0.3 & 10 & 48.4571 \\
\hline 9 & 450 & 0.5 & 30 & 60.2004 \\
\hline 10 & 300 & 0.4 & 10 & 53.1329 \\
\hline 11 & 450 & 0.3 & 30 & 49.773 \\
\hline 12 & 450 & 0.5 & 10 & 58.9227 \\
\hline 13 & 450 & 0.4 & 20 & 56.8541 \\
\hline 14 & 600 & 0.5 & 20 & 60.4276 \\
\hline 15 & 300 & 0.5 & 20 & 57.9054 \\
\hline 16 & 600 & 0.3 & 20 & 53.1083 \\
\hline 17 & 450 & 0.4 & 20 & 56.8541 \\
\hline
\end{tabular}

\section{Analysis of response surface plots and corresponding contour lines}

The fitted response surface plot was generated by the above statistical model by Design Expert program to understand the interaction of the parameters. The plots were shown in Figures-5 to 7, which depicted the interactions between two variables while keeping the other variables at their fixed levels (normally at the zero level). The shape of the contour plots indicated whether there were mutual interactions between variables or not. For example, a circle contour plot indicated that the interactions between variables were negligible. In contrast, elliptical contour plots indicated that the interactions between variables were significant ${ }^{9}$.

Figure-5 and 6 showed the level of the yield of biodiesel increased with the increasing microwave power when keeping the other variables at their fixed levels. It illustrated that the effect of microwave power on the yield of biodiesel is significant.

Figure-5 and 7 depicted that the yield of biodiesel increased clearly when $\mathrm{KOH}$ concentration increased from 0.30 to $0.50 \%$. It demonstrated that $\mathrm{KOH}$ concentration is one of the major factors. Figure- 6 and 7 showed changes in the yield of biodiesel was quite small with the extension of the in-situ transesterification time, which illustrated that the effect of in-situ transesterification time on the yield of 
biodiesel is less significant. Additionally, from Box-Behnken experimental design, it can be concluded that optimal in-situ transesterification conditions for biodiesel were microwave power $502.124 \mathrm{~W}, \mathrm{KOH}$ concentration $0.499241 \%$ and in-situ transesterification time $19.0717 \mathrm{~min}$. At this optimized condition, the predicted yield of biodiesel is $60.5887 \%$.

Table-3: The ANOVA for the response surface quadratic polynomial model

\begin{tabular}{l|r|r|r|r|r}
\hline \multicolumn{1}{c|}{ Source } & \multicolumn{1}{c|}{ Sum of Squares } & \multicolumn{1}{c|}{ df } & \multicolumn{1}{c|}{ Mean Square } & \multicolumn{1}{c}{ F Value } & \multicolumn{1}{c}{$\begin{array}{c}\text { p-value } \\
\text { Prob }>\text { F }\end{array}$} \\
\hline Model & 217.82 & 9 & 24.20 & 67.56 & $<0.0001$ \\
\hline A-Microwave power & 20.38 & 1 & 20.38 & 56.91 & 0.0001 \\
\hline B- KOH concentration & 176.47 & 1 & 176.47 & 492.65 & $<0.0001$ \\
\hline C-In-situ transesterification time & 2.64 & 1 & 2.64 & 7.38 & 0.0299 \\
\hline $\mathrm{AB}$ & 1.04 & 1 & 1.04 & 2.91 & 0.1318 \\
\hline $\mathrm{AC}$ & 0.23 & 1 & 0.23 & 0.64 & 0.4501 \\
\hline $\mathrm{BC}$ & $3.648 \mathrm{E}-004$ & 1 & $3.648 \mathrm{E}-004$ & $1.018 \mathrm{E}-003$ & 0.9754 \\
\hline $\mathrm{A}^{2}$ & 2.01 & 1 & 2.01 & 5.60 & 0.0499 \\
\hline $\mathrm{B}^{2}$ & 5.74 & 1 & 5.74 & 16.02 & 0.0052 \\
\hline $\mathrm{C}^{2}$ & 7.65 & 1 & 7.65 & 21.37 & 0.0024 \\
\hline Residual & 2.51 & 7 & 0.36 & & \\
\hline Lack of Fit & 2.51 & 3 & 0.84 & & \\
\hline Pure Error & 0.000 & 4 & 0.000 & & \\
\hline Cor Total & 220.32 & 16 & & & \\
\hline
\end{tabular}
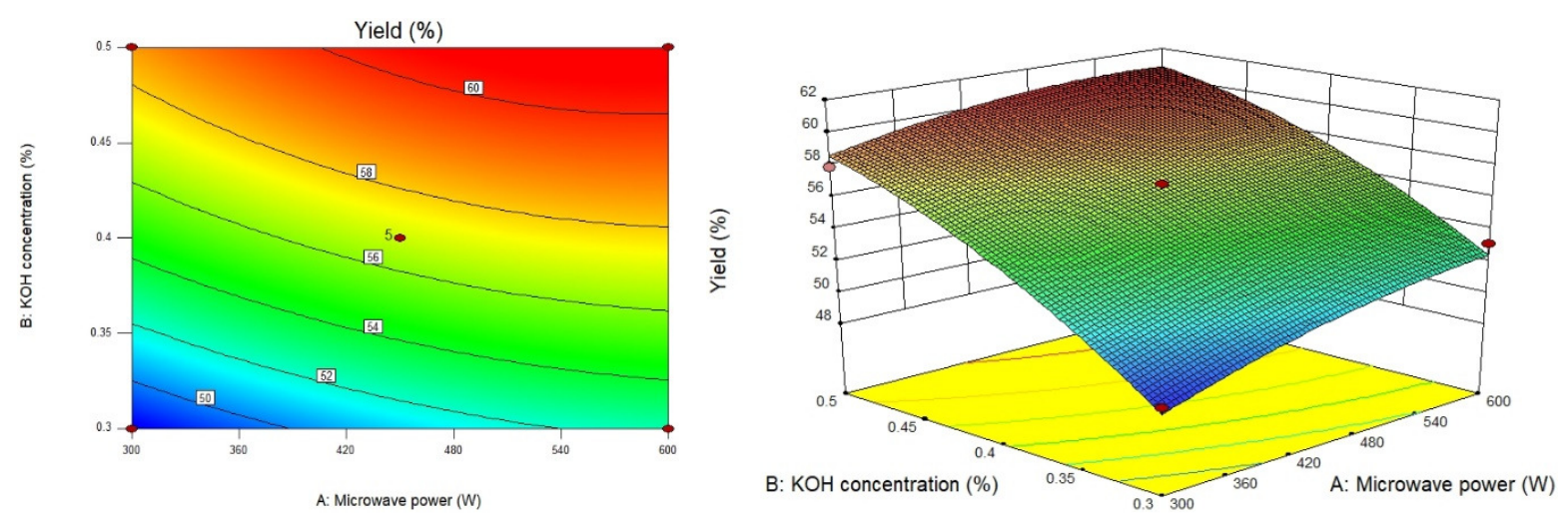

Fig.-5: Response surface plots and corresponding contour lines showing the effects of microwave power and $\mathrm{KOH}$ concentration on the yield of biodiesel

\section{Confirmative tests}

The suitability of the model equation for predicting the central point response value was tested under the central point conditions. When central point values of independent variables (microwave power $450 \mathrm{~W}$, $\mathrm{KOH}$ concentration $0.40 \%$ and in-situ transesterification time $20 \mathrm{~min}$ ) were incorporated into the regression equation, $56.8542 \%$ biodiesel yield was obtained whereas experiments at central point conditions gave a biodiesel yield of $56.8541 \%$. Thus, the actual observed values and the predicted values matched reasonably well.

\section{CONCLUSION}

Response surface methodology was adopted to optimize the in-situ transesterification conditions which enhanced the yield of biodiesel from nyamplung (Calophyllum inophyllum L.) seed using the microwave. The results suggested that statistical design methodology offered an efficient and feasible approach for the yield of biodiesel optimization. The proposed model equation illustrated the quantitative effect of variables and also the interactions among the variables. Under the central point medium condition (microwave power $450 \mathrm{~W}, \mathrm{KOH}$ concentration $0.40 \%$ and in-situ transesterification time $20 \mathrm{~min}$ ), the biodiesel yield of $56.8541 \%$ perfectly matched with the predicted value of $56.8542 \%$, which verified the practicability of this 
proposed model equation. Additionally, from Box-Behnken experimental design, it can be concluded that optimal in-situ transesterification conditions for biodiesel were microwave power $502.124 \mathrm{~W}$, KOH concentration $0.499241 \%$ and in-situ transesterification time $19.0717 \mathrm{~min}$. At this optimized condition, the predicted yield of biodiesel is $60.5887 \%$.
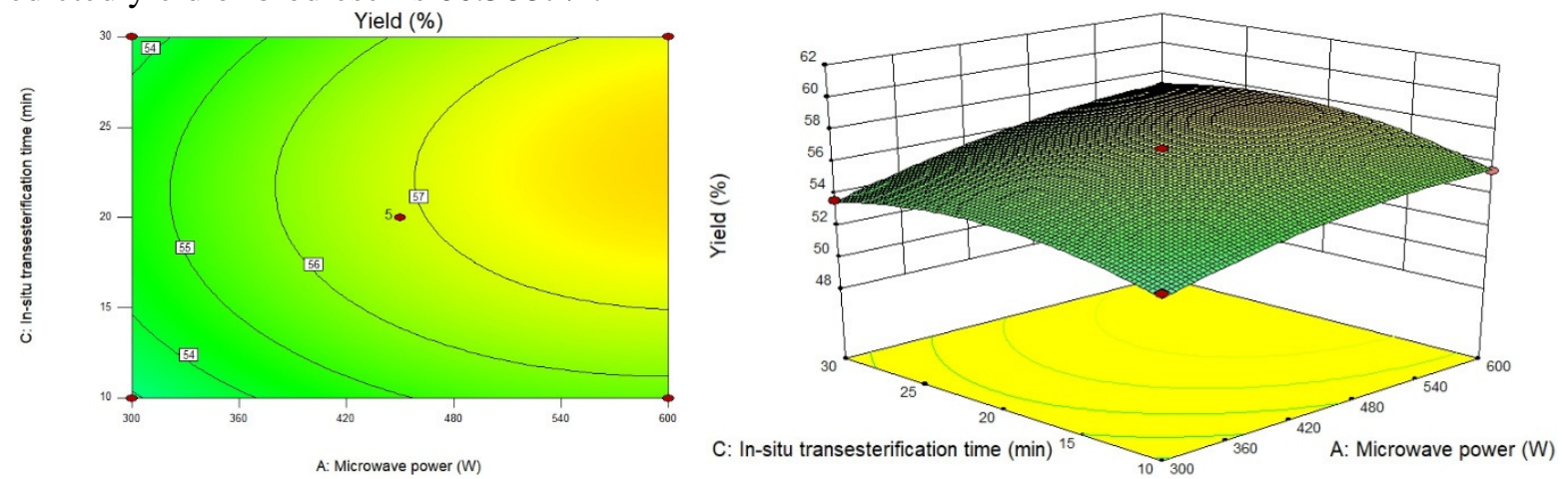

Fig.-6: Response surface plots and corresponding contour lines showing the effects of microwave power and in-situ transesterification time on the yield of biodiesel
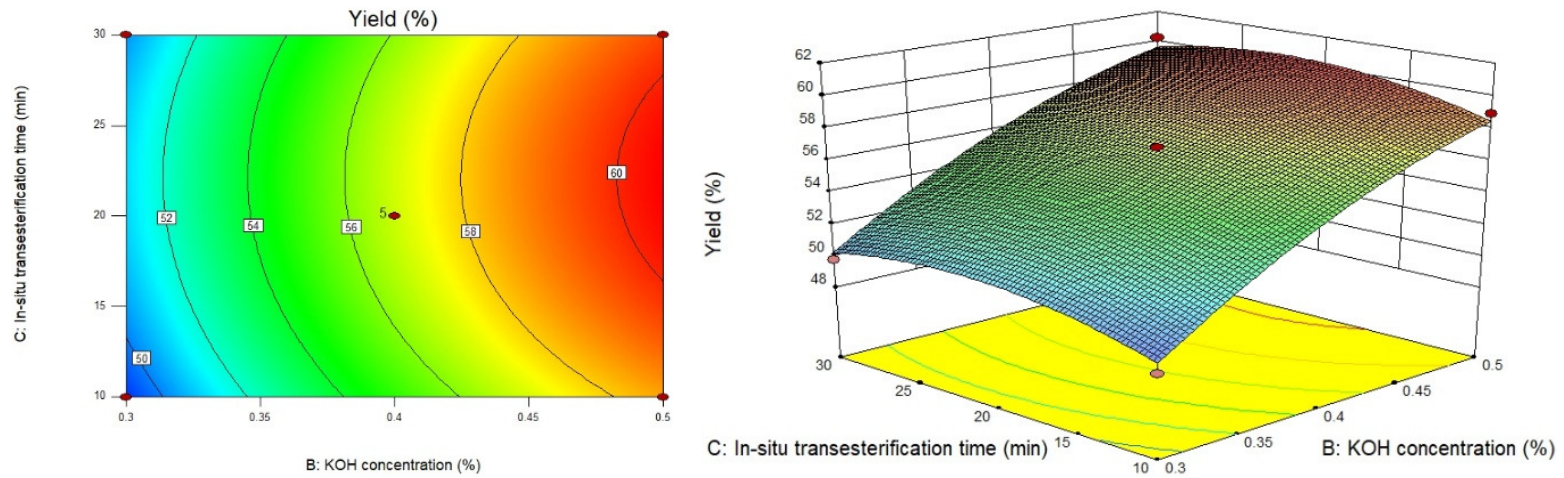

Fig.-7: Response surface plots and corresponding contour lines showing the effects of $\mathrm{KOH}$ concentration and insitu transesterification time on the yield of biodiesel

\section{REFERENCES}

1. F. Ma and M.A. Hanna, Bioresource. Technology, 70(1), 1 (1999).

2. M.J. Haas, M.S.Karen, N.M. William and A.F.Thomas, Journal of the American Oil Chemists' Society, 81(1), 83 (2004).

3. M.A. Bezerra, R.E. Santelli, E.P. Oliveira, L.S. Villar and L.A. Escaleira, Talanta, 76(5), 965 (2008).

4. C. Liyana-Pathirana and F. Shahidi, Food Chemistry, 93(1), 47 (2005).

5. Y.Tian, Z. Xu, B. Zheng and Y.M. Lo, Ultrasonics Sonochemistry, 20(1), 202 (2013).

6. L.S. Badwaik, K. Prasad and S.C. Deka, International Food Research Journal, 19(1), 341 (2012).

7. A. Raza, F. Li, X. Xu and J. Tang, International Journal of Biological Macromolecules, 94, 335 (2017).

8. Y.-B., Ji F., Dong, D.-B., Ma J., Miao, L.-N., Jin, Z.-F. Liu and L.-W., Zhang, Molecules, 17(6), 7323 (2012).

9. H.S. Kusuma and M. Mahfud, Journal of Materials and Environmental Science, 7(6), 1958 (2016).

[RJC-1803/2017] 